\title{
Does the Clinical Spectrum of Coronavirus Disease 2019 (COVID-19) Show Regional Differences?
}

\author{
So Young $\mathrm{Kim}^{1}$ (D) $\cdot$ Dae Woo $\mathrm{Kim}^{2}$ (D) \\ ${ }^{1}$ Department of Otorhinolaryngology-Head and Neck Surgery, CHA Bundang Medical Center, CHA University, Seongnam; ${ }^{2}$ Department of \\ Otorhinolaryngology-Head and Neck Surgery, SMG-SNU Boramae Medical Center, Seoul National University College of Medicine, Seoul, Korea
}

Coronavirus disease 2019 (COVID-19) emerged in Wuhan, China in December 2019. A novel coronavirus, severe acute respiratory syndrome coronavirus 2 (SARS-CoV-2), which has a transcriptome with at least 41 RNA modification sites, is the pathogen responsible for COVID-19 [1,2]. Although the COVID-19 patients confirmed before January 1, 2020 were epidemiologically associated with the Huanan SeafoodWholesale Market, the initial transmission route is still unknown [3]. Human-to-human transmission of COVID-19 has become widespread globally, and the World Health Organization declared COVID-19 to be a pandemic on March 12, 2020 [4]. The mortality rate of COVID-19 is estimated to be approximately $6.19 \%(99,887 / 1,614,951)$ in 213 countries as of April 12, 2020 [4]. Stringent quarantine systems have been implemented with social distancing actions in light of the latency period of COVID-19, which has been estimated to be about 5.2 days ( $95 \%$ confidence interval, 4.1 to 7.0 days) [3]. The frequently mild and heterogenous clinical manifestations of COVID-19 are a major obstacle in terms of clinical suspicion and preventive management.

Park et al. [5] analyzed the clinical manifestations of COVID-19 and compared the clinical features of COVID-19 between Wuhan and other regions of China. A meta-analysis established that the most common symptom of COVID-19 was fever, which was present in $91.7 \%$ of COVID-19 patients in Wuhan and in $78.1 \%$ of patients outside of Wuhan. Another common symptom, dyspnea, was also more frequently reported in Wuhan than in other regions of China $(21.1 \%$ vs. $3.8 \%)$. Although the differences in patients' initial presentation might have been influenced by delayed diagnoses in Wuhan due to the limited availability of medical doctors and facilities, the possibility that COVID-19 presents a varying range of clinical symptoms according to region has been proposed.

Another symptom that seems to show a regional difference is olfactory disturbance, which has been reported to be a common symptom in European patients, but not in Asian patients [6,7]. In a multicenter study in Europe, as many as $85.6 \%$ and $88.0 \%$ of mild-to-moderate COVID-19 patients showed anosmia and dysgeusia [6]. These symptoms preceded other symptoms in $11.8 \%$ of patients and were not accompanied by symptoms of nasal obstruction or rhinorrhea [6]. In a single-center study in US, approximately 68\% (40/59) and 71\% (42/59) of COVID-19 patients reported olfactory disturbance and dysgeusia [8]. Moreover, studies from the United Kingdom have even stated that olfactory dysfunction could be the only symptom of COVID-19 $[7,9]$. Thus, abrupt olfactory or gustatory dysfunction might be a clue that a patient has COVID-19. However, findings regarding olfaction seem to be rare in Asian populations. Only $0.93 \%$ (2/214) of COVID-19 patients from Wuhan had olfactory disturbance [10]. Although the pathophysiology of these differences remains elusive, there are three plausible explanations. First, it is possible that olfactory disturbance could be underdiagnosed in Asian populations. A study of internet search activities using Google Trends in Europe and the United States demonstrated a strong correlation between the number of COVID-19 patients and searches for olfaction-related information, which led researchers to hypothesize that olfactory disturbance could be a previously unrecognized symptom [11]. Second, it has been suggested that regional differences in the viral spike protein genotypes of SARS-CoV-2 between Asia and Europe could result in differences in viral invasiveness of the olfactory system [12]. Finally, during the last decade, many studies have documented the presence of different endotypes of sinonasal inflammation, such as chronic rhinosinusitis (CRS). Since CRS is characterized by an imbalance between external stimuli and the host response, the possibility of regional differences in the mucosal response to SARS-CoV-2 might be cautiously suggested. COVID-19 is highly infectious and has caused catastrophic impacts on populations throughout the globe. Therefore, early clin-

Copyright (C) 2020 by Korean Society of Otorhinolaryngology-Head and Neck Surgery.

This is an open-access article distributed under the terms of the Creative Commons Attribution Non-Commercial License (https://creativecommons.org/licenses/by-nc/4.0) which permits unrestricted non-commercial use, distribution, and reproduction in any medium, provided the original work is properly cited. 
ical suspicion and diagnosis may help in the eradication of COVID-19, and having a thorough understanding of the wide range of symptoms of COVID-19 can be useful for promoting appropriate levels of clinical suspicion of COVID-19 in patients with the corresponding symptoms.

\section{CONFLICT OF INTEREST}

No potential conflict of interest relevant to this article was reported.

\section{ORCID}

So Young Kim https://orcid.org/0000-0002-7361-4930

DaeWoo Kim https://orcid.org/0000-0001-5166-3072

\section{REFERENCES}

1. Lu R, Zhao X, Li J, Niu P, Yang B,Wu H, et al. Genomic characterisation and epidemiology of 2019 novel coronavirus: implications for virus origins and receptor binding. Lancet. 2020 Feb;395(10224): 565-54.

2. Kim D, Lee JY,Yang JS, Kim JW, Kim VN, Chang H. The architecture of SARS-CoV-2 transcriptome [Internet]. bioRxiv; 2020 [cited 2020 Apr 21]. Available from: https://doi.org/10.1101/2020.03.12.988865.

3. Li Q, Guan X,Wu P,Wang X, Zhou L, TongY, et al. Early transmission dynamics in Wuhan, China, of novel coronavirus-infected pneumonia. N Engl J Med. 2020 Mar;382(13):1199-207.

4. World Health Organization. Coronavirus disease (COVID-19) pandemic [Internet]. Geneva: World Health Organization; 2020 [cited
2020 Apr 21]. Available from: https://www.who.int/emergencies/diseases/novel-coronavirus-2019.

5. Park JH, Jang W, Kim SW, Lee J, Lim YS, Cho CG, et al. The clinical manifestations and chest computed tomography findings of coronavirus disease 2019 (COVID-19) patients in China: a proportion meta-analysis. Clin Exp Otorhinolaryngol. 2020 May;13(2):95-105.

6. Lechien JR, Chiesa-Estomba CM, De Siati DR, Horoi M, Le Bon SD, Rodriguez A, et al. Olfactory and gustatory dysfunctions as a clinical presentation of mild-to-moderate forms of the coronavirus disease (COVID-19): a multicenter European study. Eur Arch Otorhinolaryngol. 2020 Apr 6 [Epub]. https://doi.org/10.1007/s00405020-05965-1.

7. Gane SB, Kelly C, Hopkins C. Isolated sudden onset anosmia in COVID-19 infection. A novel syndrome? Rhinology. 2020 Apr 2 [Epub]. https://doi.org/10.4193/Rhin20.114.

8. Yan CH, Faraji F, Prajapati DP, Boone CE, DeConde AS. Association of chemosensory dysfunction and Covid-19 in patients presenting with influenza-like symptoms. Int Forum Allergy Rhinol. 2020 Apr 12 [Epub]. https://doi.org/10.1002/alr.22579.

9. Hopkins C, Surda P, Kumar N. Presentation of new onset anosmia during the COVID-19 pandemic. Rhinology. 2020 Apr 11 [Epub]. https://doi.org/10.4193/Rhin20.116.

10. Mao L, Jin H, Wang M, Hu Y, Chen S, He Q, et al. Neurologic manifestations of hospitalized patients with coronavirus disease 2019 in Wuhan, China. JAMA Neurol. 2020 Apr 10 [Epub]. https://doi.org/ 10.1001/jamaneurol.2020.1127.

11. Walker A, Hopkins C, Surda P.The use of google trends to investigate the loss of smell related searches during COVID-19 outbreak. Int Forum Allergy Rhinol. 2020 Apr 11 [Epub]. https://doi.org/10.1002/ alr.22580.

12. Benvenuto D, Giovanetti M, Ciccozzi A, Spoto S, Angeletti S, Ciccozzi M.The 2019-new coronavirus epidemic: evidence for virus evolution. J Med Virol. 2020 Apr;92(4):455-9. 